\title{
Analysis of the Environmental Performance Evaluation of Listed Companies in Jilin Province
}

\author{
Guohong Zhen ${ }^{1, a^{*}}$ and Tianwei Zhang ${ }^{2, b}$ \\ ${ }^{1}$ Higher Education Research Institute, Jilin Engineering Normal University, Changchun, Jilin, \\ 130052, China \\ ${ }^{2}$ College of Business Administration, Jilin Engineering Normal University, Changchun, Jilin, 130011, \\ China \\ a1084972009@qq.com, b1581038807@qq.com
}

Keywords: Listed companies in Jilin province; Ecological ethics; Environmental performance evaluation; Heavy pollution industry

\begin{abstract}
The environmental pollution caused by production and operation of enterprises has gained much more attention in recent years. We need to find a balance point between economic development and environmental protection. This paper will explain the connotation of environmental performance evaluation in the view of ecological ethics. The research subject is the listed companies in Jinlin Province. The overall evaluation and analysis of environmental performance will be done in this paper. At the same time, the targeted suggestions and solutions will be put forward from the government's and enterprises' view in order to promote that the environmental performance evaluation work of listed companies can go smoothly so that the sustainable development of economic society can be achieved.
\end{abstract}

\section{Introduction}

The environmental problems caused by production and operation of enterprises have become more and more serious recently. There is a hot topic that how to evaluate the environment influenced by enterprises' activities and environmental responsibilities that enterprises need to take in the academic field. At present there is a common view that the ecological environment has become the stakeholder. As a new role of enterprises, the "economic moral man" requests that enterprises must pay attention to environmental influence of production and operation so the enterprise performance evaluation must follow the new requirements.

\section{Connotation of Environmental Performance Evaluation of Enterprises}

Definition of Environmental Performance of Enterprises. Environmental performance of enterprises refers to results and effects gained by companies about environmental protection and handling environmental pollution. It is a kind of result caused by production of enterprises. It is the direct feedback of enterprise performance and is also an evaluation that whether the enterprise takes the social responsibility or not.

Definition of Environmental Performance Evaluation of Enterprises. Environmental performance evaluation is a kind of open and effective environmental management tool and is also one of the core problems of enterprise environment management. As a tool of supervising and promoting enterprises to strengthen environmental protection, it provided a criterion to evaluate the process of enterprise environmental management and effects of environmental protection. It also provides profit-relative with correct information about the environment.

The research of environmental performance evaluation started from 1970s at abroad. Many scholars did research about social responsibility performance evaluation of enterprises at first. They take report of environmental performance as an important dimension. The research of environmental performance evaluation in our nation started with ISO14000 series of environmental management standards implemented in the mid-1990s. It gradually became a hot research field after 2000. 


\section{Environmental Performance Evaluation of Enterprises in the View of Ecological Ethics}

Connotation of Ecological Ethics. Ecological ethics extends interpersonal ethics of traditional ethics concept to the ethical relationship between people and ecological environment. It specifically refers to ethical belief of the relationship between people and ecological environment, ethical attitude and conceptual system of behavior norm. It is a system respecting natural value and ethical value of rights. It can coordinate the relationship between people and ecological environment with the means of ethics. The development of ethical performance will influence the content of environmental performance evaluation of enterprises and it requires that enterprises should take ecological environment as the stakeholder and take ecological responsibilities.

Dimensions of Environmental Performance Evaluation of Enterprises in the View of Ecological Ethics. The core of enterprise environmental performance evaluation is enterprise's ecological responsibility. The ecological benefit and ecological friendliness are two principles of it. The clean production, green management, saving energy and protecting the environment, this four norms in the ecological ethics system are taken as an evaluation dimension.

The first one clean production. Clean production refers that people can utilize energy and resources reasonably as their demand has been satisfied, at the same time, people need to take producing technology and measures to protect ecological environment. Environmental performance evaluation of enterprises is based on life cycle theory of production. The quantitative index is the main data. The environmental performance evaluation of enterprises is analyzed mainly from the view of procurement, investment, using efficiency and consumption of raw materials under this dimension.

The second one is green management. Green management refers that whether enterprises can merge environmental protection, sustainable development and other concepts into enterprise management consciously under the supervision of government policy and the public. The environmental performance evaluation of enterprises is analyzed mainly from the view of designing concept of production, marketing concept, establishment of protecting and supervising environment institute, release of enterprise's environmental report and other aspects under this dimension.

The third one is saving resources. Enterprises pay less attention to saving resources during the production process because natural resources belong to public goods. On the one hand, the enactment of regulations related to enterprises, the production concept and utilization of harmful and recycling raw resources should be taken into consideration under this dimension. On the other hand, the consuming rate and cycling rate of resources, defective rate of products, the service life of products and recovering rate of products should be also taken into consideration.

The last one is protecting the environment. The investment in environmental protection is the main reflect in protecting the environment. The environmental performance evaluation of enterprises is analyzed from the view of environmental protection degree of marketing methods, the investing cost of environmental protection training, the proportion of environment-protecting equipment investment, expenditure of environment-protecting activities and other aspects under this dimension.

\section{The Overall Introduction of Environmental Performance Evaluation of Listed Companies in Jilin Province}

General Introduction of Listed Companies in Jilin Province. There were 40 listed companies involving cars, concrete, real estate, biological medicine, non-bank finance, electricity, computer software, etc until to March 31th 2017. According to dividing criteria of heavy pollution industry in Environmental Information Disclosure Guide for Listed Companies (Feedback Edition) released by the Department of Conservation in September 2010, the following 20 listed companies belong to heavy pollution industry as shown in Table 1 . 
Table 1 Content of listed companies belonging to heavy pollution industry in Jilin Province

\begin{tabular}{|c|c|}
\hline Stock Code & Stock Abbreviation \\
\hline 000030 & Fuao Shares \\
\hline 000420 & Jilin Chemical Fiber \\
\hline 000546 & Jinyuan Shares \\
\hline 000766 & Tonghua Jinma \\
\hline 000875 & Jilin Electricity Shares \\
\hline 002338 & Aopu Photoelectric \\
\hline 002566 & Yisheng Pharmaceutical co. \\
\hline 000545 & Jinpu Titanium Industry \\
\hline 000623 & Jilin Aodong \\
\hline 000800 & Faw Car \\
\hline 002118 & Zixin Pharmaceutical \\
\hline 300108 & Shuanglong Shares \\
\hline 600856 & Zhongtian Energy \\
\hline 600881 & Yatai Company \\
\hline 600867 & Tonghua Dongbao \\
\hline 600432 & Jien Nickel Industry \\
\hline 600365 & Tonghua Wine Shares \\
\hline 600148 & Changchun Yidong \\
\hline 600333 & Changchun Feul Gas \\
\hline 600742 & Faw Car Fuwei \\
\hline
\end{tabular}

Analysis about Overall Introduction of Environmental Performance Evaluation of Listed Companies in Jilin Province. There are 20 heavy pollution listed companies being surveyed among listed companies in Jilin province. From 2013 to 2015, 5 companies separately released social responsibility report among 20 heavy pollution listed companies. They are Jilin Aodong, Faw Car,Jien Nickel Industry,Tonghua Dongbao and Yatai Company. Other 15 companies had not released social responsibility report, and the information about their environmental achievement almost appeared in the annual report. The content of environmental performance evaluation will be analyzed based on the annual report and social responsibility report from 2013 to 2015 .

The first one is Faw Car. This company continued the concept of sustainable development in 2013. This company strictly observes national and local regulations and discharging index about environmental protection. This company carries out their work strictly based on all the environment-protecting management institute, constantly promotes energy-saving and environment-protecting and puts the concept of environmental protection into production and operating. This company totally dealt with 1.4875 million tons of sewage during the whole year. All the living sewage and production sewage totally meet the national secondary standard for Integrated Sewage Discharge Standard. During the whole year of 2014, this company totally dealt with more than 1 million tons of sewage. All the living sewage and production sewage totally meet the national secondary standard for Integrated Sewage Discharge Standard.

The second one is Tonghua Dongbao. "Two undone" was the basic principle for this company in 2013. This company will not do actions that may threaten national and peoples' interest. The company will not do actions that may threaten environment and resources. The company constantly upgrades system of electricity, heating power and water resource so that maximum energy utilization efficiency can be ensured through the most advanced technology. The cost of discharging pollution was 200.016 thousand yuan and the cost of environmental protection was 245 thousand yuan in 2013. The concept of environmental development was "building a factory, developing economy, protecting environment and making citizens happy" in 2014 and 2015. The cost of discharging pollution was 207.660 thousand yuan in 2014. The cost of discharging pollution was 
200.016 thousand yuan in 2015 .

The third one is Jilin Aodong. This company struggled to achieve production ecologicalization based on improving resources utilizing efficiency and environmental protection in 2013. This company put forward that the green development must be the sustainable development that cannot damage resources and environment. This company insists the principle of reducing, re-utilizing and saving. The company will get economic achievement and social achievement and keep harmonious development of economy, society and environment. This company constantly improved craftsmanship, innovated technology, strengthened production management, reduced energy consumption and saved resources based on the principle of reducing, re-utilizing and saving in 2015.

The fourth one is Jien nickel industry. This company paid much attention on environmental protection from 2013 to 2015 . The company strictly implements environmental protection based on the principle of observing laws and regulations, saving and reducing consumption, preventing constant pollution and environment-friendly Jinie brand. The company constantly invests money in improving environment in order to govern company's environment. The company has dealt and governed all kinds of pollution produced in the production process. The company constantly puts more power in dealing with three kinds of pollution so that the company can achieve inner cycling economic development.

The fifth one is Yatai company. Environmental protection was the important content of sustainable development from 2013 to 2015 . The company insists the principle of preventing firstly, preventing and dealing, snythetical governance and achieving environmental protection and sustainable development. The company needs to take responsibility for environmental protection. Expenditure of discharging pollution was 14.943474 million yuan in 2013. Expenditure of discharging pollution was 16.573490 million yuan in 2014. Expenditure of discharging pollution was 1.484287 million yuan in 2015 .

Environmental Performance Evaluation of Listed Companies Releasing Environmental Information in Annual Report. There were 12 companies releasing environment information in the major events of annual report in 2013. They were Fuao Shares, Jilin Electricity Shares, Aopu Photoelectric, Yisheng Pharmaceutical co., Changchun Yidong, Changchun Feul Gas, Faw Car Fuwei, Jinyuan Shares, Tonghua Jinma, Zixin Pharmaceutica, Jilin Chemical Fiber, and Jinpu Titanium Industry. The environmental benefit from government was 40 million yuan mentioned in balance of payments of Jinyuan Shares' annual report. The environmental benefits from government was 30 million yuan mentioned in balance of payments of Zixin Pharmaceutical's annual report. The major events in the annual report of Jinlin chemical fiber were mainly about saving energy, reducing discharge, regulating the environment and carrying out clean production. The environmental benefit from government was 120 million yuan mentioned in balance of payments of Jinpu Titanium Industry's annual report. There were so many contents about environmental protection in major events of Aopu Photoelectric. The whole passage of major events of Changchun Feul Gas was mainly about environmental protection. The content of major events of Aopu Photoelectric was mainly about environmental protection. Half of the content about major events of Tonghua Jinma was mainly about environmental protection. It also involved expenditure of sanitation and discharging.

There were 11 companies releasing environment information in the major events of annual report in 2014. They were Tonghua Jinma, Jinyuan Shares, Fuao Shares, Jinpu Titanium Industry, Aopu Photoelectric, Yisheng Pharmaceutical co., Changchun Feul Gas, Changchun Yidong, Faw Car Fuwei, and Jilin Chemical Fiber. Expenditure of greening factory in the annual report was 91.2592 million yuan. Expenditure of discharging pollution in annual report of Changchun Feul Gas was 3.308678 million yuan. The environmental benefit from government was 5.6 million yuan. Expenditure for environmental protection in annual report of Faw Car Fuwei was 12 million yuan. The benefit to prevent pollution from government was 25.243 thousand yuan in annual report of Yisheng Pharmaceutical co.. Expenditure of discharging and protecting environment was 3.750537 million yuan in annual report of Jilin Chemical Fiber. Other contents about environmental 
protection were the same as the last year. The major events in annual report was mainly about environmental protection, cycling economy and clean production. The contents about environmental protection and energy saving were the same as last year in Aopu Photoelectric.

There were 12 companies releasing environment information in the major events of annual report in 2015. They were Jinpu Titanium Industry, Tonghua Jinma, Jilin Electricity Shares, Aopu Photoelectric, Yisheng Pharmaceutical co., Changchun Yidong, Changchun Feul Gas, Faw Car Fuwei, Zhongtian Energy, Fuao company and Jilin Chemical Fiber.

\section{Problems of Environmental Performance Evaluation of Listed Companies in Jilin Province}

Less Attention to Environmental Protection. About half companies have not disclosed environment information based on investigation of 40 listed companies in Jilin province. Among listed companies that disclose information, there are some listed companies disclosing less information about environment information. In conclusion, enterprises need to improve their environmental protection consciousness.

Lack Regulated Environmental Performance Evaluation System. It is so difficult for enterprises to implement environmental performance evaluation because there is no standardized regulation of environmental performance evaluation. Jien nickel industry is the best company to do an environmental performance evaluation. When the company disclose enough environment information in their social responsibility report. However, we can easily notice that their disclosing information lacks comparability because there is no standardized environmental performance evaluation system as reference at present.

Defective Disclosing Information about Environment Information. Enterprises have selecting tendency towards disclosing environment information because there is no standardized mode of releasing information about environmental performance evaluation of listed companies so that information is not subjective and complete enough. For example, among 20 companies belonging to heavy pollution companies, there were so many companies not making changes and adjustment in disclosing environment information in the past 3 years and disclosing ways were simplex. It is obvious that disclosing information is not complete enough.

\section{Suggestions and Countermeasures of Environmental Performance Evaluation of Listed Companies in Jilin Province}

In the View of Government. The first measure is to improve laws and regulations. We think that a set of complete laws and regulations is the basic guarantee to push enterprises to do environmental performance evaluation. Government or some departments should gradually establish complete laws and regulations, administration systems and technological research systems that can promote enterprises to develop sustainably and protect the environment.

The second measure is to improve environmental performance evaluation system. Government should coordinate with the Ministry of Finance, the Department of Conservation and China Securities Regulatory Commission to strengthen theoretical study of environment accountancy, make environment accountancy criteria and regulate contents of environmental performance evaluation so that quality of disclosing information can be improved and government can supervise implementation of enterprises' environment responsibility better.

In the View of Enterprises. The first one is that enterprises should transfer developing strategy based on the current situation. Firstly enterprises need to optimize the production structure and strengthen technological innovation. When enterprises evaluate achievements and scale, they need to carry out energy-saving and environment-friendly development strategy. And then enterprises need to borrow advanced practical experience to promote technological progress, reduce cost in environmental governance and achieve economic and social profits.

The second one is that enterprises should establish inner controlling regulations of enterprises' environment management. Enterprises should establish environment management institute and make it clear including managing occupation, division of labor, operating process and implementing 
state. In addition, enterprises should combine relating laws and regulations of nations with the situation of the company to establish enterprise's regulation about saving resources and protecting environment. Enterprises should also establish supervising and examining system and implement award and punishment regulations so that enterprises can put resources saving and environment protection into practice.

\section{Acknowledgements}

Fund project: One of the periodic research results of the Jilin social science fund project "Study on the Index System of Environmental Performance Evaluation of Listed Companies in Jilin"(Project number: 2016B92).

\section{References}

[1] X.M.Li and Y.J.Fan: Review and Prospect of Enterprise Environmental Performance Evaluation at Home and Abroad[J], Business Economy, 2014-10.(In Chinese)

[2] X.Y.Jin: Research and Influence on Environmental Performance Evaluation of Listed Companies[J], Commercial Accounting, 2013-15.(In Chinese)

[3] J.B.Song and D.N.Li: The Theoretical Research and Practical Enlightenment of Enterprise Environmental Responsibility and Environmental Performance[J], Journal of Renmin University of China, 2013-3.(In Chinese)

[4] J.Xu and M.H.Jiang: Research on the Dimension of Enterprise Environmental Performance Evaluation Based on Corporate Social Responsibility[J], University of International Business and Economics, 2014-5. (In Chinese)

[5] X.M.Li: Research on the Dimension of Enterprise Environmental Performance Evaluation from the Perspective of Ecological Ethics[J], Economist, 2014-2.(In Chinese)

[6] Y.F.Wu: Research on Enterprise Environmental Accounting Information Disclosure Based on Environmental Performance Evaluation[D], Beijing Jiaotong University, 2015-4.(In Chinese) 